\title{
L-Asparaginase-Induced Complete Response in a Relapsed Patient with Epstein-Barr Virus and Cytotoxic Peripheral T-Cell Lymphoma Not Otherwise Specified
}

\author{
Tsutomu Takahashi ${ }^{1}$, Fumiyoshi Ikejiri ${ }^{1}$, Chie Onishi ${ }^{1}$, Koshi Kawakami ${ }^{1}$, Masaya Inoue ${ }^{2}$, \\ Takaaki Miyake ${ }^{1}$, Junko Tanaka ${ }^{1}$, Asuka Araki ${ }^{3}$, Riruke Maruyama ${ }^{3}$, \\ Koichi Ohshima ${ }^{4}$ and Junji Suzumiya ${ }^{2}$
}

\begin{abstract}
We present a patient with Epstein-Barr virus (EBV)-positive cytotoxic peripheral T-cell lymphoma, not otherwise specified (PTCL-NOS) who was successfully treated using only L-asparaginase. A 46-year-old Japanese man was diagnosed with EBV-positive cytotoxic PTCL-NOS. Although he underwent chemotherapy using multiple agents, he relapsed with hemophagocytic syndrome. L-asparaginase treatment was initiated at $6,000 \mathrm{U} / \mathrm{m}^{2}$ on days $1,3,5,10$, and 12 together with prednisolone at $1 \mathrm{mg} / \mathrm{kg}$. Although he developed grade 2 liver dysfunction and grade 2 coagulopathy, the patient achieved complete response status. Finally, he underwent allogeneic bone marrow stem cell transplantation, and he is currently still alive without disease at 24 months after the start of L-asparaginase therapy.
\end{abstract}

Key words: peripheral T-cell lymphoma-NOS, L-asparaginase, Epstein-Barr virus, cytotoxic molecule, hemophagocytic syndrome

(Intern Med 49: 2505-2508, 2010)

(DOI: 10.2169/internalmedicine.49.4083)

\section{Introduction}

Peripheral T-cell lymphoma, not otherwise specified (PTCL-NOS) is heterogeneous, and it does not correspond to any of the specifically defined types of mature T-cell lymphomas in the current WHO classification (1). PTCLNOS is the most common T- or NK-cell (T/NK-cell) lymphoma, comprising $25.9 \%$ of NK/T-cell lymphomas (2). The prognosis for patients with PTCL-NOS is poor because of poor responses to anthracycline-containing regimens and frequent relapses (2). Furthermore, a standard therapy for PTCL-NOS has not been established. Although some reports have demonstrated the efficacy of L-asparaginase in refractory patients with extranodal NK-cell lymphoma (ENKL) $(3,4)$, few reports have shown the efficacy of Lasparaginase for PTCL-NOS $(5,6)$. We present a patient with EBV-positive cytotoxic PTCL-NOS who was successfully treated using only L-asparaginase.

\section{Case Report}

A 46-year-old Japanese man was admitted with generalized lymphadenopathy without hepatosplenomegaly or skin rash. Computed tomography (CT) revealed multiple enlarged lymph nodes of the neck, axilla, mediastinum, pulmonary hilus, para-aorta, pelvis, and groin. Laboratory examination showed normal blood cell counts but increased levels of serum LDH (751 IU/L; normal range 100-200), CRP (6.4 mg/ $\mathrm{dL})$, and soluble interleukin-2 receptor (sIL-2R) (7,677 U/ $\mathrm{mL}$; normal range 144-518). The serum titers of antiEpstein-Barr virus (EBV) antibodies showed viral capsid antigen (VCA)-IgG $\times 320$ (normal range $<\times 10$ ), EBVassociated antigen (EBNA) $\times 10$ (normal range $<\times 10$ ), and

${ }^{1}$ Department of Hematology, Shimane University Hospital, Izumo, ${ }^{2}$ Cancer Center, Shimane University Hospital, Izumo, ${ }^{3}$ Department of Pathology, Shimane University Hospital, Izumo and ${ }^{4}$ Department of Pathology, Kurume University, Kurume

Received for publication June 13, 2010; Accepted for publication August 20, 2010

Correspondence to Dr. Tsutomu Takahashi, ben2106t@med.shimane-u.ac.jp 

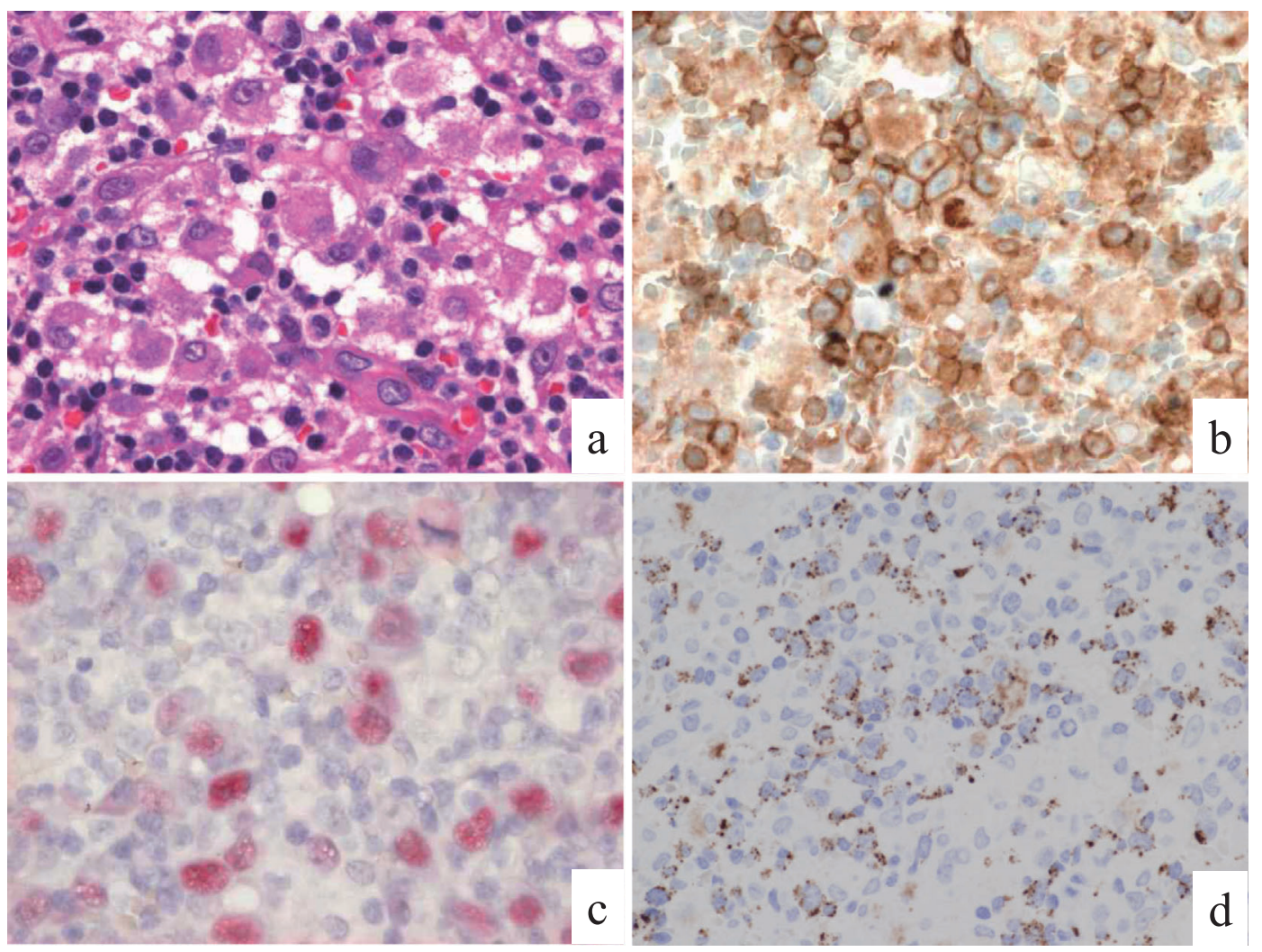

Figure 1. Microscopic appearance of a lymph node at initial presentation. (a) Hematoxylin and Eosin staining, ×400; (b) CD3, ×400; (c) EBER in situ hybridization, $\times 400$; (d) TIA-1, $\times 200$.

VCA-IgM $\times 10$ (normal range $<\times 10$ ). Anti-human immunodeficiency virus antibody was negative. The bone marrow aspirate showed no infiltrating atypical cells. Biopsy of a neck lymph node revealed effacement of the nodal architecture and diffuse proliferation of medium and large atypical lymphoid cells, which were intermingled with some Hodgkin-like cells. Flow cytometry showed that the lymphoma cells were $\mathrm{CD} 2+, \mathrm{CD} 3+, \mathrm{CD} 4+, \mathrm{CD} 5+, \mathrm{CD} 7+$, CD8-, CD56-, and TCR $\alpha \beta+$. Immunohistochemical staining revealed that the abnormal lymphoid cells were positive for CD3, CD4, and TIA-1 but negative for CD8, CD15, CD79a, PAX5, CD56, and EBV-latent membrane antigen 1. Most Hodgkin-like giant cells were positive for CD30 and EBER by in situ hybridization (Fig. 1). Southern blot analysis of a lymph node (LN) specimen revealed a single band for the EBV terminal repeat region, and polymerase chain reaction (PCR) analysis showed a monoclonal gene rearrangement of the T-cell receptor (TCR) gamma and beta chain genes. Although anti-human T-lymphotropic virus type-1 (HTLV-1) antibody was positive, no monoclonal integration of HTLV-1 could be found by Southern blotting. We diagnosed the patient as PTCL-NOS, Ann-Arbor stage IIIA, and we treated him with one cycle of CHOP (cyclophosphamide, doxorubicin, vincristine, and prednisolone), one cycle of VCAPAMP-VECP (vincristine, cyclophosphamide, doxorubicin, ranimustine, vindesine, etoposide, carboplatin, and prednisolone) (7), and two cycles of CHASE (cyclophosphamide, cytarabine, etoposide, and dexamethasone) (8). His generalized lymphadenopathy initially improved, but lymph node regrowth and bone marrow infiltration with hemophagocytic syndrome appeared four months after the start of treatment. Although the levels of EBV-DNA in peripheral blood were low (110 copies $\left./ 10^{6} \mathrm{WBC}\right)$ at the initial diagnosis, they increased markedly to 40,000 copies $/ 10^{6}$ white blood cells at that time. Although the patient underwent methylprednisolone pulse therapy, neither the hemophagocytic syndrome nor the lymphadenopathy improved. L-asparaginase treatment was initiated at $6,000 \mathrm{U} / \mathrm{m}^{2}$ on days $1,3,5,10$, and 12 together with prednisolone at $1 \mathrm{mg} / \mathrm{kg}$. Both the hemophagocytic syndrome and the generalized lymphadenopathy improved within a few days of the start of L-asparaginase treatment. The levels of LDH also gradually decreased (Fig. 2). Lymphoma cells and hemophagocytosis disappeared from the bone marrow on day 15 after the start of Lasparaginase treatment, and no residual disease was observed by PET-CT on day 59 (Fig. 3). The levels of EBVDNA in peripheral blood decreased to 260 copies $/ 10^{6}$ white blood cells. Adverse reactions including grade 2 liver dysfunctions and grade 2 coagulopathy occurred following Lasparaginase administration, but these conditions resolved completely. The patient underwent allogeneic bone marrow stem cell transplantation from an HLA-matched sibling donor on day 69 after the start of L-asparaginase treatment. At present, he is still alive without disease or serious complications at 24 months after the start of L-asparaginase therapy. 


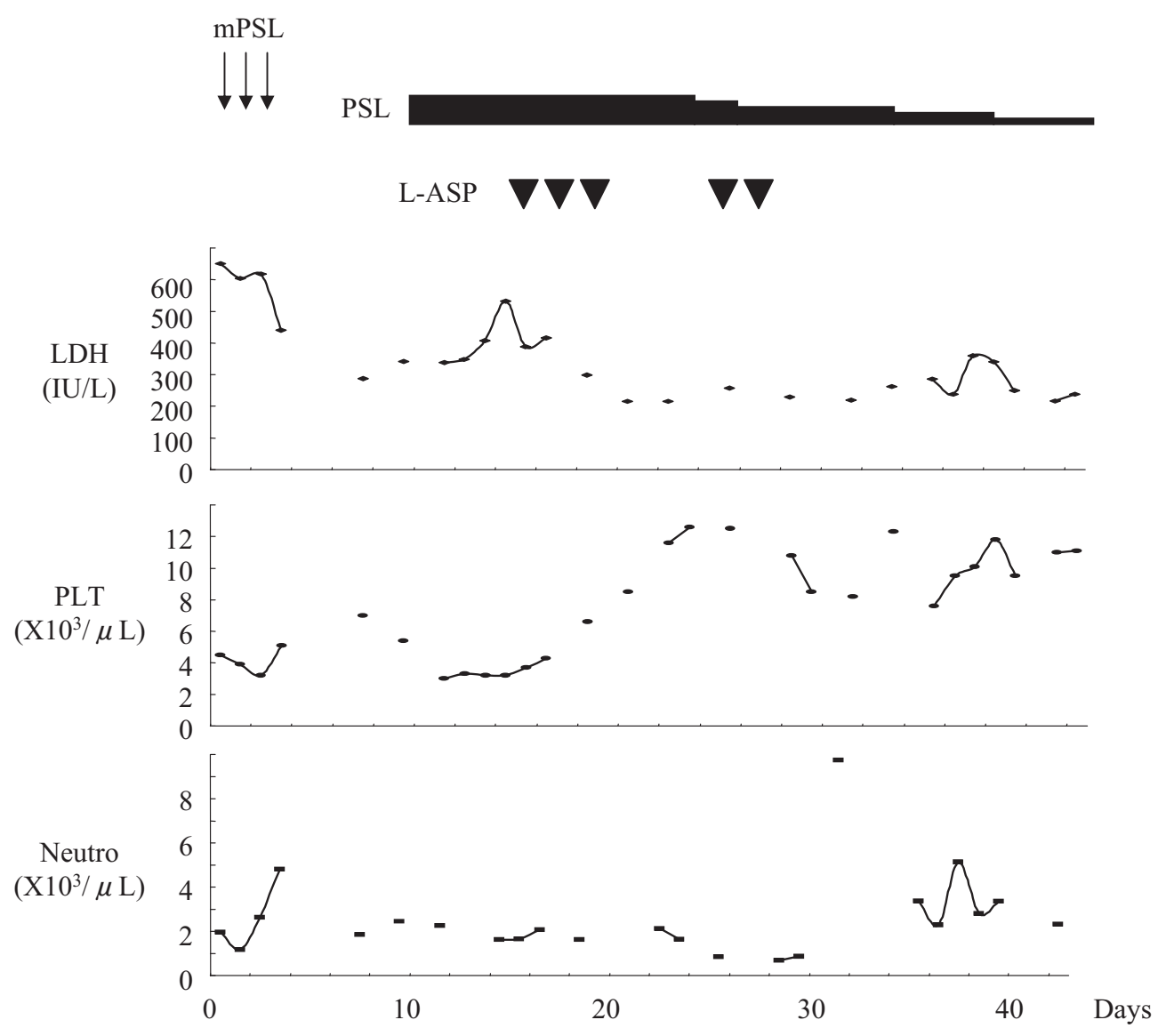

Figure 2. Clinical course of the patient. Abbreviations: L-ASP: L-asparaginase, mPSL: methylprednisolone, PSL: prednisolone, LDH: lactate dehydrogenase, PLT: platelet count, Neutro: neutrophil count

Pre treatment
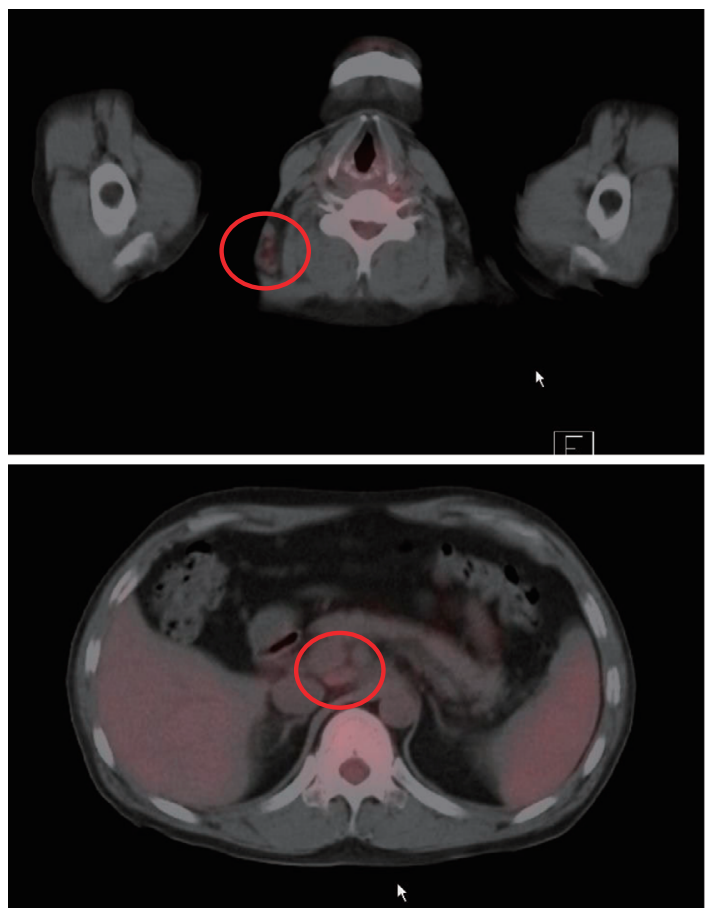

\section{Post treatment}
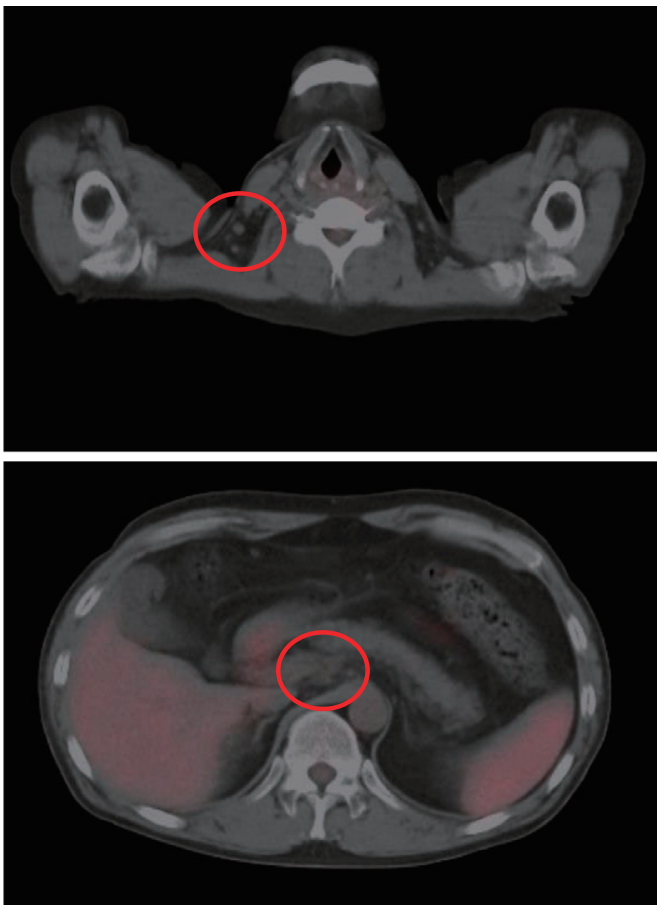

Figure 3. FDG-PET/CT findings. FDG-PET/CT before L-asparaginase treatment showed the accumulation of FDG in the neck and para-aortic lymph nodes and hematosplenomegaly. These findings improved following L-asparaginase administration. 


\section{Discussion}

There have been previous reports about prognostic factors for PTCL-NOS, including the presence of EBV (9), the expression of cytotoxic molecules such as granzyme B and TIA-1 (10), and hemophagocytic syndrome complications (11). The present patient demonstrated some adverse prognostic factors, including EBV positivity, cytotoxic molecule expression, and multiple drug resistance. However, the administration of L-asparaginase alone resulted in the achievement of CR status. L-asparaginase is a naturally occurring enzyme and exerts its antitumor activity by depleting circulating pools of L-asparagine, which is an essential amino acid for protein synthesis (12). Some reports have shown that L-asparaginase can be effective against extranodal NK/T-cell lymphomas $(3,4)$; however, the mechanism by which L-asparaginase affects lymphomas in vivo remains unclear. Ando and colleagues reported that L-asparaginase could induce apoptosis of NK-cell lymphoma cells in vitro (13). Extranodal NK/T-cell lymphoma cells and cytotoxic T-cell lymphoma cells share certain characteristics, such as the presence of EBV and cytotoxic molecules. A few reports have indicated that L-asparaginase is effective against PTCL as well as NK/T-cell lymphomas $(5,6)$. Based on the outcome of the present case and previous reports, Lasparaginase may be effective for the treatment of cytotoxic T-cell lymphomas and NK-cell lymphomas. It has been reported that the SMILE regimen (methotrexate, ifosfamide, dexamethasone, etoposide, and L-asparaginase) is effective against relapsed or refractory $\operatorname{ENKL}(14,15)$. Although the effectiveness of the SMILE regimen for the treatment of PTCL-NOS has not been reported, based on the present findings, we conjectured that this regimen might be effective against PTCL-NOS as well as ENKL. To test this hypothesis, we recently initiated an international phase II study of the SMILE regimen for PTCL (NKTSG-03) in Japan, Korea, Hong Kong, and China. The results of this study are eagerly anticipated because they may reveal the types of PTCL that can be effectively treated with L-asparaginase.

\section{Acknowledgement}

The authors thank Associate Prof. Ritsuro Suzuki at the Department of HSCT Data Management \& Biostatistics, Nagoya University School of Medicine, for invaluable discussions.

\section{References}

1. Pileri SA, Weisenburger DD, Sng I, et al. Peripheral T-cell lymphoma,not otherwise specified. In: WHO Classification of Tumours of Haematopoietic and Lymphoid Tissues. Swerdlow SH, Campo E, Harris NL, Eds. IARC, Lyon, France, 2008: 306-308.

2. Vose J, Armitage J, Weisenburger D. International peripheral Tcell and natural killer/T-cell lymphoma study: pathology findings and clinical outcomes. J Clin Oncol 26: 4124-4130, 2008.

3. Jaccard A, Petit B, Girault S, et al. L-asparaginase-based treatment of 15 western patients with extranodal NK/T-cell lymphoma and leukemia and a review of the literature. Ann Oncol 20: 110-116, 2009.

4. Yong W, Zheng W, Zhu J, et al. L-asparaginase in the treatment of refractory and relapsed extranodal NK/T-cell lymphoma, nasal type.. Ann Hematol 88: 647-652, 2009.

5. Obama K, Tara M, Niina K. L-asparaginase induced complete remission in Epstein-Barr virus positive, multidrug resistant, cutaneous T-cell lymphoma. Int J Hematol 69: 260-262, 1999.

6. Tong H, Ren Y, Qian W, et al. Clinicopathological study on peripheral T-cell non-Hodgkin lymphoma with bone marrow involvement: a retrospective analysis from China. Int J Hematol 90: 303$310,2009$.

7. Tsukasaki K, Utsunomiya A, Fukuda H, et al. VCAP-AMP-VECP compared with biweekly CHOP for adult T-cell leukemialymphoma: Japan Clinical Oncology Group Study JCOG9801. J Clin Oncol 25: 5458-5464, 2007.

8. Ogura M, Kagami Y, Taji H, et al. Pilot phase I/II study of new salvage therapy (CHASE) for refractory or relapsed malignant lymphoma. Int J Hematol 77: 503-511, 2003.

9. Dupuis J, Emile JF, Mounier N, et al. Prognostic significance of Epstein-Barr virus in nodal peripheral T-cell lymphoma, unspecified: A Groupe d'Etude des Lymphomes de l'Adulte (GELA) study. Blood 108: 4163-4169, 2006.

10. Asano N, Suzuki R, Kagami Y, et al. Clinicopathologic and prognostic significance of cytotoxic molecule expression in nodal peripheral T-cell lymphoma, unspecified. Am J Surg Pathol 29: 1284-1293, 2005.

11. Tong H, Ren Y, Liu H, et al. Clinical characteristics of T-cell lymphoma associated with hemophagocytic syndrome: comparison of T-cell lymphoma with and without hemophagocytic syndrome. Leuk Lymphoma 49: 81-87, 2008.

12. Copur MS, Rose M, Gettinger SN. Miscellaneous chemotherapeutic agents. In: Cancer Principles \& Practice of Oncology. 8th Ed. Devita VT, Lawrence TS, Rosenberg SA, Eds. Lippincott Williams \& Wilkins, Philadelphia, 2008: 490-491.

13. Ando M, Sugimoto K, Kitoh T, et al. Selective apoptosis of natural killer-cell tumours by L-asparaginase. Br J Haematol 130: 860868, 2005.

14. Yamaguchi M, Suzuki R, Kwong YL, et al. Phase I study of dexamethasone, methotrexate, ifosfamide, L-asparaginase, and etoposide (SMILE) chemotherapy for advanced-stage, relapsed or refractory extranodal natural killer (NK)/T-cell lymphoma and leukemia. Cancer Sci 99: 1016-1020, 2008.

15. Yamaguchi M, Kwong Y, Maeda Y, et al. Phase II study of SMILE chemotherapy for newly-diagnosed stage IV, relapsed or refractory extranodal NK/T-cell lymphoma, nasal type: NKTSG study. J Clin Oncol 28: 584s, 2010 (\#8044 abstract).

(C) 2010 The Japanese Society of Internal Medicine http://www.naika.or.jp/imindex.html 